\title{
Microbial control of arthropod-borne disease
}

\author{
Miguel A Saldaña', Shivanand Hegde², Grant L Hughes $2,3,4,5 /+$ \\ ${ }^{1}$ University of Texas Medical Branch, Department of Microbiology and Immunology, Galveston, TX, USA \\ ${ }^{2}$ University of Texas Medical Branch, Department of Pathology, Galveston, TX, USA \\ ${ }^{3}$ University of Texas Medical Branch, Institute for Human Infections and Immunity, Galveston, TX, USA \\ ${ }^{4}$ University of Texas Medical Branch, Center for Biodefense and Emerging Infectious Disease, Galveston, TX, USA \\ ${ }^{5}$ University of Texas Medical Branch, Center for Tropical Diseases, Galveston, TX, USA
}

Arthropods harbor a diverse array of microbes that profoundly influence many aspects of host biology, including vector competence. Additionally, symbionts can be engineered to produce molecules that inhibit pathogens. Due to their intimate association with the host, microbes have developed strategies that facilitate their transmission, either horizontally or vertically, to conspecifics. These attributes make microbes attractive agents for applied strategies to control arthropod-borne disease. Here we discuss the recent advances in microbial control approaches to reduce the burden of pathogens such as Zika, Dengue and Chikungunya viruses, and Trypanosome and Plasmodium parasites. We also highlight where further investigation is warranted.

Key words: microbiome - paratransgenesis - mosquito - arbovirus - vector control - malaria

Vector-borne diseases (VBD) are responsible for inordinate mortality, morbidity and economic loss worldwide. One of the most important groups of pathogentransmitting vectors are the mosquitoes, including species within the Anopheles, Aedes and Culex genera. Particularly well studied are the Anopheles mosquitoes that vector Plasmodium parasites that cause malaria in humans. While five Plasmodium parasites cause malaria, Plasmodium falciparum is the major cause of this disease in sub-Saharan Africa (Snow et al. 2005). Aedes mosquitoes are notorious for vectoring arthropodborne viruses (arboviruses) including flaviviruses such as Dengue virus (DENV), Yellow fever virus (YFV) and Zika virus (ZIKV), and also the Alphavirus, Chikungunya virus (CHIKV) (Bhatt et al. 2013, Weaver \& Lecuit 2015, Weaver et al. 2016). Culex mosquitoes are known vectors of West Nile virus (WNV) and other encephalitic viruses, as well as filarial nematodes. Other than mosquitoes, Phlebotominae and Simuliidae flies are responsible for transmitting pathogens that cause Leishmaniasis, Onchocerciasis, as well as other neglected tropical diseases. In Africa, several species of tsetse flies vector Trypanosomes that cause sleeping sickness in humans and nagana in livestock. Further vectors include Triatomine bugs that transmit Trypanosomes that cause Chagas disease, which infects an estimated 6 million people in Latin America (Bern 2015). Ticks also transmit a variety of pathogens including viral, bacterial and protozoan parasites (Dantas-Torres et al. 2012).

doi: 10.1590/0074-02760160373

Financial support: GLH was supported by a NIH grant (R21Al124452) and

a University of Texas Rising Star award. MAS was supported by a NIH grant (2T32AI007526).

+ Corresponding author: glhughes@utmb.edu

Received 17 August 2016

Accepted 16 November 2016
While traditional and contemporary control strategies have made great progress to control malaria and other neglected tropical diseases, the incidence of other diseases has been on the rise. Current disease prevention strategies often rely on vector control as effective vaccines are not available for many pathogens, however vector control strategies are becoming ineffective, mainly due to insecticide resistance emerging in many vectors (Naqqash et al. 2016, Ranson \& Lissenden 2016). Taken together, novel strategies for control of VBD are urgently required. The current global ZIKV pandemic, and the reemergence of YFV in Africa and Leishmania in the Middle East stress this need for novel control tools against emerging and re-emerging pathogens (Al-Salem et al. 2016, Barrett 2016, Weaver et al. 2016). To this end, microbial-based intervention strategies are gaining considerable traction as a novel means to control VBD. In this review we highlight the recent advances in the use of symbionts to suppress pathogens in their vectors by drawing upon examples of viral, bacterial and fungal symbiosis in various vector species. Most studies have focused on mosquito vectors but where possible we include examples from other vector systems.

The vector microbiome - The advent of High Throughput Sequencing (HTS) technologies has expanded our understanding of the composition of the microbiome of many vector species. The microbiome is composed of viruses, bacteria, fungi and protozoa, however pathogens that vectors transmit can also be considered as constituents of the microbiome. Microbial association with the host can be facultative or obligate, and the nature of these host-microbe interactions, which range across a spectrum from parasitic to mutualistic, is likely fluid and depends on factors such as the host and environment (Casadevall et al. 2011). Microbes can have an intracellular or extracellular lifestyle, and possibly transition between both. Microbiota can also preferentially reside in specific host organs and tissue including 
the midgut (the lumen or gut epithelia), fat body, salivary glands, ovaries and testes (Sharma et al. 2014, Segata et al. 2016, Tchioffo et al. 2016). In several of these tissues, the microbe has the opportunity to directly interact with invading pathogens.

Our most comprehensive understanding of vector microbiomes is derived from mosquitoes. Studies utilising HTS have revealed that the microbiome is often dominated by relatively few taxa, can be highly variable, and that this variation is influenced by factors such as host life stage, host sex, the sampling technique, and the biotic and abiotic environment (Boissière et al. 2012, Osei-Poku et al. 2012, Coon et al. 2014, Gimonneau et al. 2014, Duguma et al. 2015, Buck et al. 2016, Segata et al. 2016). HTS techniques are currently most effective in examining the bacterial microbiome, and such work suggests mosquitoes have a microbiota comprised of bacteria within the phyla Proteobacteria, Bacteriodetes and Actinobacteria, encompassing taxa such as Serratia, Pseudomonas, Aeromonas, Elizabethkingia, Enterobacter, and Acintobacter (Boissière et al. 2012, Osei-Poku et al. 2012, Coon et al. 2014, Gimonneau et al. 2014, Hughes et al. 2014a, Duguma et al. 2015, Buck et al. 2016, David et al. 2016, Segata et al. 2016). Similar to mosquitoes, ticks have been found to have diverse and complex microbiomes, with the microbial composition influenced by life history traits and diet (Menchaca et al. 2013). The microbiome of lone star tick, Amblyomma americanum, is composed of the pathogens Anoplasma and Ehrlichia as well as other symbiotic bacteria within the phyla Proteobacteria, Bacteroidetes and Firmicutes (Jasinskas et al. 2007, Fryxell \& DeBruyn 2016). Microbiome analysis of the Rocky mountain wood tick, Dermacentor andersoni identified four prominent genera of bacteria: Rickettsia, Francisella, Arsenophonus and Acinetobacter (Clayton et al. 2015). In tsetse flies, three vertically transmitted bacterial symbionts, Wigglesworthia, Sodalis, and Wolbachia are often present in the host, in addition to other environmentally acquired commensal bacteria (Wang et al. 2013b).

There are few studies investigating the fungal microbiome (mycobiome) of vector species. Most approaches that do explore the diversity of fungal microbes in insects exploit culture-based methods (Ignatova et al. 1996, Marti et al. 2006, Gusmão et al. 2010). A yeast strain, Wickerhamomyces anomalus, was found in both the midgut and reproductive system of the Asian malaria vector, Anopheles stephensi (Ricci et al. 2011), and six different fungal species have been found in the midgut of sandfly vectors (Akhoundi et al. 2012). However, recently, HTS was used to examine the mycobiome of Aedes triseriatus and Aedes japonicus (Muturi et al. 2016a). This study found twenty-one distinct fungal OTUs, 15 of which were shared between Ae. triseriatus and Ae. japonicus (Muturi et al. 2016a). The majority of fungal taxa in these Aedes species were from the Ascomycota phylum (Muturi et al. 2016a). Similarly, the Ae. albopictus mycobiome is dominated by fungi within the Ascomycota in addition to other taxa within phylum $\mathrm{Ba}$ sidiomycota (Muturi et al. 2016b). While the role of the mycobiome in regulating vector competence is poorly understood, it is likely that fungi and yeast can have a similar impact on pathogen transmission as bacteria, as fungi produce antimicrobial molecules and influence host immunity (Lemaitre et al. 1996, Martin et al. 2015, Wang et al. 2015, Angleró-Rodríguez et al. 2016). For instance, it was recently reported that Penicillium chrysogenum increases the intensity of Plasmodium infection in Anopheles mosquitoes by suppressing mosquito immunity (Angleró-Rodríguez et al. 2016).

Characterisation of the viral microbiome (virome) of disease vectors is now also gaining attention. Metagenomic sequencing of mosquitoes revealed the presence of several species of plant, animal and bacterial viruses in the mosquito virome (Ng et al. 2011, Chandler et al. 2015). Similar studies in ticks also identified several viral families, including previously unknown viruses (Tokarz et al. 2014, Xia et al. 2015, Sakamoto et al. 2016). The effect on the host of many of these viruses is yet to be elucidated. In contrast, we know that tsetse flies harbor a salivary gland hypertrophy virus (SGHV), which is a rod-shaped, enveloped DNA virus that is transmitted both horizontally and vertically, and can become pathogenic, causing hypertrophy of the salivary glands and reduced fecundity and lifespan (Wang et al. 2013b). Interestingly, it appears that there is an interaction of SGHV with microbial symbionts residing in the fly, as aposymbiotic flies have reduced viral loads (Boucias et al. 2013, Wang et al. 2013a).

Complex host-microbe interactions dictate microbiome and host homeostasis of arthropods. While the factors that shape the composition of the microbiome are still under investigation in most systems, it is clear that environmental conditions (Zouache et al. 2010, Wang et al. 2011, Minard et al. 2013), and host genetics (Kumar et al. 2010, Oliveira et al. 2011, Stathopoulos et al. 2014, Soares et al. 2015, Pang et al. 2016) are important. For instance, silencing of an antimicrobial peptide in Triatoma infestans elevated bacterial load in the midgut which subsequently reduces Trypanosoma cruzi parasites, indicating that host control of the microbiome can influence pathogen dynamics (Buarque et al. 2016). Bacterial genetics also appears to be an important determinant of gut colonisation (Maltz et al. 2012, Pei et al. 2015), however like much of the work examining bacterial genetic factors that influence persistence in the mammalian gut, this area of study is in its infancy in arthropods. While we have a limited understanding of the factors that regulate homeostasis in vectors, insights can be drawn from model insects where these processes have been examined in more detail (Buchon et al. 2013, Erkosar et al. 2013, Broderick 2016). In insects, microbial interactions are known to influence many diverse phenotypes and processes including host nutrition, reproduction, immunity, behavior, survival and evolution (Engel \& Moran 2013, Lewis \& Lizé 2015, Shropshire \& Bordenstein 2016, van Tol \& Dimopoulos 2016). In arthropod vectors, these phenotypes can have important implications for vectorial capacity. Additionally, members of the microbiome can themselves modulate vector competence for a variety of pathogens, either by direct interactions with the pathogen or indirectly mediated by the host (Dennison et al. 2014, Hegde et al. 2015). While the influence of the microbiome on vector competence is 
likely multifaceted and complex, interplay between the microbiota and host immunity is one process that can alter pathogen levels (Xi et al. 2008, Dong et al. 2009, Carissimo et al. 2015). Given these interactions, it is unsurprising that these interactions can also be reciprocated, whereby pathogen infection, which stimulates host immunity, can alter the microbiome (Xi et al. 2008, Ramirez et al. 2012, Zouache et al. 2012, Vieira et al. 2015, Zink et al. 2015, Muturi et al. 2016a). This highlights the intricate dynamism between the host and the microbiome, which in part, is shaped by host immunity. From an applied perspective, these microbe-mediated alterations in vector competence can be harnessed for novel microbial pathogen control strategies.

Innate anti-pathogen activity of microbes - Wolbachia - The most extensively developed microbial strategy to alter the vector competence of mosquitoes utilises Wolbachia. Wolbachia is a common bacterial endosymbiont that infects approximately $60 \%$ of insects (Hilgenboecker et al. 2008). It has been extensively studied for its ability to manipulate the reproduction of its host, which enables the bacterium to spread through insect populations (Werren et al. 2008). Cytoplasmic incompatibility (CI) is one of the most widespread reproductive mechanisms Wolbachia employs. CI occurs when an infected male mates with a female that is uninfected, or infected with an incompatible strain of Wolbachia. These crosses result in embryonic lethality and provide a fitness advantage to the infected female counterparts in the population, facilitating Wolbachia's spread within insect populations (Werren et al. 2008). Wolbachia-mediated $\mathrm{CI}$ is being exploited as a population suppression tool termed incompatible insect technique (IIT) (reviewed in Bourtzis et al. 2014), and has been deployed to suppress Aedes mosquito populations (O'Connor et al. 2012). However, after it became evident that the antiviral properties of Wolbachia, which were first discovered in Drosophila (Hedges et al. 2008, Teixeira et al. 2008) also occurred in mosquitoes against a broad range of pathogens (Kambris et al. 2009, Moreira et al. 2009, Hughes et al. 2011b), the use of this bacteria for population replacement control strategies has been explored with vigor. The ability of the bacterium to confer pathogen interference, and to rapidly invade populations due to a high vertical transmission rate and the induction of CI, make Wolbachia an attractive agent for applied control.

Wolbachia can interfere with the development of diverse pathogens transmitted by mosquitoes. The antipathogen phenotype is particularly noticeable when a strain of Wolbachia is artificially transferred (transinfected) into a vector creating a novel strain-host combination (Hughes \& Rasgon 2014). Most attention has focused on Ae. aegypti, which is generally thought to be naturally uninfected by Wolbachia, however, intriguingly, an infection was recently reported in mosquitoes collected in Florida, USA (Coon et al. 2016). Two strains of Wolbachia were found in these mosquitoes, which were phylogenetically related to the $w \mathrm{AlbA}$ and $w \mathrm{AlbB}$ strains in Ae. albopictus (Coon et al. 2016). Transinfected Ae. aegypti have reduced vector competence to several important arboviruses such as DENV (Moreira et al. 2009, Walker et al. 2011, Joubert et al. 2016), YFV (Hurk et al. 2012), CHIKV (Moreira et al. 2009, Aliota et al. 2016b) and ZIKV (Aliota et al. 2016a, Dutra et al. 2016). Wolbachia infected Ae. aegypti are also less competent vectors for filarial nematodes (Kambris et al. 2009) and Plasmodium parasites (Moreira et al. 2009). In addition to arbovirus control approaches in Aedes mosquitoes, Wolbachia-based strategies are also under investigation to inhibit Japanese encephalitis virus (JEV) vectored by Culex tritaeniorhynchus (Jeffries \& Walker 2015).

Antiviral activity is also seen when novel strains are transinfected into Ae. albopictus (Blagrove et al. 2011), which is naturally infected with two strains of Wolbachia, wAlbA and wAlbB. Here, these resident strains were removed by antibiotic treatment before introduction of the novel wMel strain from Drosophila. These $w$ Mel-infected Ae. albopictus have decreased vector competence for DENV compared to an uninfected line and the naturally double infected mosquitoes (Blagrove et al. 2011). The effect of natural Wolbachia infections on pathogen dynamics is more difficult to assess, as uninfected individuals need to be identified, or the infection cleared with antibiotic treatment, for comparison. Antibiotic treatment can also have confounding effects such as altering the microbiome (Hughes et al. 2014a) or affecting mitochondria (Ballard \& Melvin 2007). With these caveats in mind, native Wolbachia infections have been shown to reduce WNV in $C x$. quinquefasciatus (Glaser \& Meola 2010) and DENV and CHIKV in Ae. albopictus (Mousson et al. 2010, 2012), but it is important to note that these naturally infected mosquitoes are still competent vectors. Conversely, the native Wolbachia infection in Culex pipiens has been shown to exacerbate Plasmodium titer compared to their uninfected counterparts (Zélé et al. 2014), and Wolbachia also protects the vector against the deleterious fitness effects of the parasite, thus extending host lifespan, which has implications for pathogen transmission (Zélé et al. 2012).

The development of Wolbachia control strategies for human malaria appears more complex compared to arboviral pathogens. Aside from the propensity of Wolbachia to increase Plasmodium titer in some circumstances (Hughes et al. 2012, Baton et al. 2013, Murdock et al. 2014), which may be an artifact due to the method of infection or artificial nature of some tripartite combinations used in laboratory studies (reviewed in Hughes et al. 2014b), there are challenges with stably transinfecting Anopheles mosquitoes. To overcome these issues, transient infection was used to rapidly asses the effect of $\mathrm{Wol}$ bachia on Plasmodium, and this technique found that the $w$ MelPop and wAlbB Wolbachia strains blocked P. falciparum (Hughes et al. 2011b). The wMelPop strain has also been shown to interfere with Plasmodium berghei, a murine malaria model (Kambris et al. 2010). In groundbreaking work from Bian et al. (2013) An. stephensi was stably infected with the wAlbB strain of Wolbachia. These novel infections induced CI in An. stephensi and substantially blocked $P$. falciparum (Bian et al. 2013), offering promise for the use of this bacterium in malaria control approaches. However, the infection also exerted a considerable fitness cost on the mosquito (Bian et al. 2013, Joshi et al. 2014), which would need to be overcome for Wolbachia to spread in field populations. 
Recently, natural Wolbachia infections in some Anopheles populations have been discovered (Baldini et al. 2014, Buck et al. 2016, Shaw et al. 2016). These studies, in addition to the transinfection of An. stephensi (Bian et al. 2013), have overturned the dogma that Anopheles mosquitoes were recalcitrant to Wolbachia infection and were naturally uninfected across their range. The native infections were shown to affect host fitness and reduce Plasmodium loads compared to uninfected conspecifics (Shaw et al. 2016). More work is required to determine if these natural infections can be exploited for Plasmodium control or if the resident strains would complicate the spread of more useful transinfected strains (Jeffries $\&$ Walker 2016). Similarly, the recently discovered natural infections in Ae. aegypti could have implications for implementation of Wolbachia-based strategies (Coon et al. 2016). Other bacterial symbionts that are known to manipulate insect reproduction (Duron et al. 2008), in a similar fashion to Wolbachia such as Spiroplasma (Terenius et al. 2008, Segata et al. 2016), and bacteria related to Arsenophonus (Briones et al. 2008) have been found in mosquitoes, but their effect on host reproduction and vector competence remains to be elucidated.

Gut associated microbes - Bacteria that reside predominately within the midgut of vectors can have profound anti-pathogenic effects that could be exploited in novel vector control strategies. Early studies examined the interaction between microbes and pathogens in Anopheles-Plasmodium and Triatomine-Trypanosome systems (Beier et al. 1994, Straif et al. 1998, Eichler \& Schaub 2002). Today, most research in this area focuses on Aedes and Anopheles mosquitoes and the influence of the microbiome on arboviruses and Plasmodium parasites, respectively. Research that investigates the influence of gut microbes on pathogen dynamics is usually undertaken by perturbing the microbiome by antibiotic treatment or through administration of cultured bacteria to the vector. Alternative approaches included using antibodies raised against the microbiota to manipulate the microbiome, or rearing gnotobiotic lines (Noden et al. 2011, Coon et al. 2014). Antibiotic treatment has been shown to increase the titer of DENV in Ae. aegypti, JEV in Culex bitaeniorhynchus, T. cruzi in Rhodnius prolixus and Plasmodium in Anopheles mosquitoes (Mourya \& Soman 1985, Xi et al. 2008, Dong et al. 2009, Kumar et al. 2010, Rodrigues et al. 2010, Castro et al. 2012). These findings suggesting that the microbiota is antagonistic to invading pathogens. Re-infection of bacterial taxa into the vector enables the anti-pathogenic properties of specific microbes to be identified. Using this approach, isolates of Enterobacter, Acinetobacter, Pantoea, Pseudomonas, Serratia and Elizabethkingia have been shown to inhibit Plasmodium (Cirimotich et al. 2011, Bahia et al. 2014, Ramirez et al. 2014). The Enterobacter Esp_Z isolate was shown to produce reactive oxygen species (ROS) that inhibited the malaria parasite (Cirimotich et al. 2011), while other bacterial taxa may have distinct modes of action against Plasmodium (Bahia et al. 2014). Intriguingly, a specific strain of Serratia that has enhanced motility suppresses Plasmodium compared to a non-motile strain, providing insights into the mechanism behind the interference phenotype and highlighting the importance of bacterial inter-strain variation on vector competence (Bando et al. 2013). In other work, Enterobacter, Proteus and Paenibacillus species have been shown to inhibit La Crosse virus (LACV) and DENV (Joyce et al. 2011, Ramirez et al. 2012). Strikingly, a Chromobacterium isolate has both anti-Plasmodium and anti-viral properties, and reduces the survival of larvae and adult mosquitoes, possibly linked to the secretion of metabolites such as cyanide (Ramirez et al. 2014). Secreted molecules that have anti-pathogen and entomopathogenic activity could be harnessed for novel biotechnology applications. Such products could be used against the vector or the pathogens they transmit, or alternatively, exploited as novel pharmaceuticals for use in humans or livestock.

In addition to studies on arboviruses and malaria, bacterial microbes can alter pathogens in other vector species. Serratia, which is a dominant component of the gut microbiome of Triatomine bugs, appears to be an important determinant of Trypanosome infection (Azambuja et al. 2004, da Mota et al. 2012). The trypanocidal activity of Serratia could be related to prodigiosin production, which affects the mitochondrial activity of the parasite, and the ability of this bacterium to attach to the parasite (Castro et al. 2007, Genes et al. 2011). Studies in sandflies imply that microbes reduce Leishmania parasite load (Schlein et al. 1985) while tsetse flies cured of their symbionts were more susceptible to Trypanosome infection (Wang et al. 2009, Weiss et al. 2013). In ticks, both positive and negative interactions between symbionts and pathogens have been observed. Rickettsia bellii is negatively correlated with Anaplasma marginale infection, and reductions in a Francisella symbiont leads to a lower titer of the pathogenic Francisella novicida (Gall et al. 2016). Perturbing the microbiome of Ixodes scapularis altered the peritrophic matrix of the arachnid and subsequently led to a reduction in the spirochete, Borrelia burgdorferi (Narasimhan et al. 2014).

Pathogen enhancement mediated by microbes has also been documented in mosquitoes. Suppression of the midgut microbiota by antibiotic treatment in Anopheles mosquitoes decreased O'nyong nyong virus (ONNV) infections (Carissimo et al. 2015), indicating that constituents of the microbiota are required for pathogen infection. Reinfection of live, but not heat-killed bacteria, into antibiotic treated mosquitoes reverted viral titers to levels comparable to untreated controls (Carissimo et al. 2015). These effects are in contrast to what is observed with Plasmodium which increase in titer after antibiotic treatment of mosquitoes (Dong et al. 2009, Kumar et al. 2010, Rodrigues et al. 2010). A similar pathogen enhancement effect was seen in Ae. aegypti re-infected with Serratia odorifera, which increases both DENV and CHIKV infections (Apte-Deshpande et al. 2012, 2014). The ability of bacterial taxa to both enhance and suppress pathogens in insects suggests complex interplay between the host, the microbiome and the pathogen, dictates vector competence. Furthermore, specific vector-pathogen-microbe combinations may have unique outcomes, which means intervention strategies need to be scrutinised thoroughly before implementation. 
While studies examining the role of the bacterial microbiome on arthropod biology are expanding and providing insights into alternative approaches to control arthropod-borne disease, we have a very limited knowledge on the role of the virome or mycobiome on vector biology and vector competence. The yeast $W$. anomalus produces a toxin that has in vitro antiplasmodial activity (Valzano et al. 2016). Studies investigating the entomopathogenic fungi Beauveria bassiana indicate this fungal pathogen suppresses DENV titer in Ae. aegypti through activation of the Toll and Jak-Stat immune pathways (Dong et al. 2012). This antiviral property further supports the use of this microbe for novel microbial biopesticide applications. Recently it has become evident that mosquitoes are naturally infected with insect-specific viruses (ISV). These viruses, which are phylogenetically diverse, infect mosquitoes but do not replicate within vertebrate cells (Blitvich \& Firth 2015, Bolling et al. 2015, Vasilakis \& Tesh 2015). Interestingly, it appears that ISV can suppress arboviruses in mosquitoes, likely due to a process known as superinfection exclusion (Newman et al. 2011, Bolling et al. 2012, Crockett et al. 2012, Kenney et al. 2014, Kuwata et al. 2015, HallMendelin et al. 2016). Most studies have used in vitro systems and focused on insect-specific flaviviruses although an insect-specific alphavirus has been shown to alter Sindbis virus titer in vivo (Nasar et al. 2015). These findings have raised the possibility that fungi and ISV could be used in applied control strategies but before this can be achieved, a more thorough understanding of the biology of these microbes is required. Studies should focus on examining the ecological range and infection frequency of these microbes in natural mosquito populations, understanding the nature of their association with the host and other microbes, and investigate the mechanisms in which they are acquired and transmitted.

Engineering microbes to convey anti-pathogen activity - Microbes that reside within the gut of vectors can be engineered to secrete anti-pathogen molecules, an approach known as paratransgenesis. Paratransgenic studies were initially pioneered in Triatomine bugs for control of Chagas disease (Durvasula et al. 1997, Beard et al. 2002). Here, the symbiotic bacterium Rhodococcus rhodnii was genetically manipulated to express antimicrobial peptides that were antagonistic to $T$. cruzi, the parasitic protozoan that causes Chagas disease. Expression of cecropin A eliminated or reduced the number of T. cruzi within $R$. prolixus (Durvasula et al. 1997). Ingeniously, the copraphagic tendencies, or probing of fecal droplets, of the insect were exploited to deliver the transgenic symbiont to the vector. An artificial mimic of $R$. prolixus feces spiked with transgenic $R$. rhodnii, which was probed by nymphs, facilitated symbiont acquisition (Durvasula et al. 1997). In field trials, around half of the nymphs exposed to the mimic were infected throughout their development (Durvasula et al. 1999).

After these seminal studies, Beard et al. (2002) detailed the requirements for successful paratransgenic strategies. These include: that a symbiotic relationship occur between the microbe and the host; that the microbe be readily culturable and transformable; transfor- mation should not alter the symbiotic relationship with the host, alter microbial fitness compared to wild type conspecifics or make the microbe pathogenic; that the effector gene product should be secreted to interact with the pathogen; and that there must be an efficient way to deliver the microbe into the vector population.

Paratransgenesis is also being explored in other vector species, particularly Anopheles mosquitoes for the control of malaria, using bacterial microbes as delivery vehicles. Earlier studies investigated engineering effector protein secretion systems from Pantoea agglomerans, which was isolated from Anopheles mosquitoes (Riehle et al. 2007, Bisi \& Lampe 2011). Importantly, transgenic bacteria administered to mosquitoes in sugar meals were seen to rapidly proliferate following a blood meal and had minimal impact on life history traits of the mosquito (Wang et al. 2012). The secretion of several effector proteins antagonistic to Plasmodium using the HlyA secretion system from $P$. agglomerans was shown to significantly reduce the intensity of P. falciparum in the mosquito gut (Wang et al. 2012). The mode of action and the targets of the anti-Plasmodium effector molecules has been comprehensively reviewed (Wang \& Jacobs-Lorena 2013). Asaia is another candidate for paratransgenic control of malaria. This bacterium is important for larval development of Anopheles mosquitoes, is genetically tractable, appears to be easily acquired by mosquitoes and is vertically inherited to progeny (Favia et al. 2007, Chouaia et al. 2012). Secretion of the effector proteins, Scorpine and the anti-Pbs21 scFv-Shival toxin fusion protein, from Asaia reduced oocyst intensity of $P$. berghei in the midgut compared to control bacteria (Bongio \& Lampe 2015). Elizabethkingia is another dominant member of the mosquito microbiome that is transstadially transmitted. This bacterium has been genetically altered and reinfected into Anopheles and Aedes mosquitoes (Chen et al. 2015a), however the use of this microbe in paratransgenic control approaches may need to be reconsidered since it is potentially a human pathogen (Frank et al. 2013) and given its natural resistance to several antibiotics. Genomic and further epidemiological analysis may clarify if strains present in mosquitoes are the source of infection in humans (Kukutla et al. 2014, Teo et al. 2015, Garay et al. 2016).

Paratransgenic approaches are also being developed for the control of Trypanosomes vectored by tsetse flies. The symbiont Sodalis glossinidius has been manipulated to release anti-trypanosome nanobodies (antigenbinding molecules) in the fly gut (de Vooght et al. 2012, 2014). Strategies have proposed to couple paratransgenic Sodalis with Wolbachia, and exploit Wolbachia's CI-mediated drive to spread the transgenic symbiont through the population. Modeling suggests that if Wolbachiainduced mortality is low and the anti-trypanosome molecule is effective, the incidence of disease could be successfully reduced (Medlock et al. 2013). Preliminary experiments such as the identification and culturing of microbes have been accomplished for paratransgenesis strategies in Phlebotomus argentipes sand flies for control of Leishmania (Hillesland et al. 2008).

In comparison to bacterial paratransgenic approaches, there are few examples of the use of viral or fungal symbionts for paratransgenic control. While fungal paratransgenic studies are limited in medical vector species, 
approaches are also being investigated to control agricultural pathogens (Hughes et al. 2011a). The identification of culturable fungi and yeast associated with vectors provides candidate microbes for further investigation (Ricci et al. 2010, 2011, Martin et al. 2015, Steyn et al. 2015). In a subtle variation on the paratransgenic theme, the fungal insect pathogen Metarhizium anisopliae has been manipulated to express effector molecules to inhibit Plasmodium in Anopheles mosquitoes (Fang et al. 2011). Expression of the peptide SM1, a single chain antibody, or the antimicrobial toxin scorpine, significantly reduced sporozoites in the salivary gland. Impressively, the expression of 8 repeats of SM1 and scorpine as a fusion protein reduced Plasmodium intensity by $98 \%$ (Fang et al. 2011). M. anisopliae is an insect pathogen that infects mosquitoes through direct contact with the cuticle, which may enhance infection of the vector, but its pathogenic nature would likely mean that continual release of the microbe would be required.

Viral paratransgenesis research has mainly focused on Densoviruses. Aedes DNV (AeDNV), which can be pathogenic to the mosquito host (Ledermann et al. 2004), has been manipulated to express foreign genes (Afanasiev et al. 1999). Expression of a toxin from AeDNV increased the pathogenic effects of the virus compare to wild type virus in Ae. albopictus (Gu et al. 2010), offering promise for this strategy to be employed as a biopesticide. An Anopheles gambiae DNV (AgDNV) has been characterised and used as an expression platform (Ren et al. 2008, Suzuki et al. 2014). Unlike AeDNV, AgDNV is not pathogenic to the mosquito host and has minimal impact on mosquito survival (Ren et al. 2014). While DNVs can be used to express proteins in mosquitoes and the virus infects relevant organs in the insect to interfere with invading pathogens, there are some obstacles that need to be overcome before these viruses can be used in the field for paratransgenesis. DNVs have small genomes, which can limit the size of the inserted transgenes and they often require wild type virus for effective viral packaging. In an elegant approach, recombinant AeDNV were engineered to express microRNAs that target host genes or to sequester host miRNA using antisense miRNA sponges (Liu et al. 2016). This strategy overcomes some of the challenges associated with expressing larger genes from these viruses and enables the use of RNAi, rather than effector molecules, for vector control.

Microbes expressing RNAi - A promising alternative to paratransgenesis has emerged whereby microbes are engineered to deliver double stranded (dsRNA) to insects. RNAi is a powerful tool to manipulate transcription that has been used extensively to elucidate the function of many insect genes. In particular this technology has been extremely valuable in identifying mosquito pathways and genes that influence pathogen dynamics (Xi et al. 2008, Garver et al. 2009, Souza-Neto et al. 2009) and other aspects of insect biology useful for mosquito control (Isoe et al. 2011, Thailayil et al. 2011, Figueira-Mansur et al. 2013). The RNAi pathway is also a natural defense strategy used by insects to inhibit invading viral pathogens (Keene et al. 2004, SánchezVargas et al. 2009), and therefore lends itself to develop- ment for applied pathogen control of arboviruses. This approach is very flexible in that potentially any gene in the vector could be manipulated. In addition, a vast array of interfering molecules can be delivered to the vector to manipulate gene expression, including short-hairpin RNAs (shRNA), long hairpin RNAs (lhRNA), artificial microRNAs (amiRNA) or miRNA sponges. Engineered microbes could deliver multiple RNAi molecules, allowing several synergistic intervention strategies to be undertaken simultaneously, reducing the risk of evolution of resistance to a particular intervention approach. Theory predicts that viruses will not have the potential to evolve to such combinatorial intervention approaches (Leonard \& Schaffer 2005), and experimental evidence shows that polycistronic expression of multiple shRNA can effectively inhibit DENV (Xie et al. 2013).

Delivery of RNAi to insects has been achieved with viruses, bacteria and yeast. For approaches targeting vector species, most strategies target host genes that when silenced induce mortality. These approaches can be considered as a novel species-specific insecticide. Other approaches have targeted genes that are important for reproduction, thereby reducing the fecundity of the insect. The use of bacteria for RNAi delivery is more complicated since the RNase III enzyme of the bacterium can degrade double stranded RNA (dsRNA). For many years, RNase III mutants of Escherichia coli have been used for RNAi silencing in the nematode Caenorhabditis elegans (Timmons et al. 2001). Similar approaches with RNase III mutant $E$. coli are effective for RNAi delivery to Ae. aegypti mosquitoes and $R$. prolixus bugs (Whyard et al. 2015, Taracena et al. 2015), while a $R$. rhodnii RNase III mutant was used to express RNAi in $R$. prolixus (Whitten et al. 2016). In contrast, wild type $R$. rhodnii bacteria were used to deliver RNAi molecules to Reduviid bugs that reduced fecundity of the insect (Taracena et al. 2015). Similarly, fungi have been used to express RNAi targeting several essential host genes to kill agricultural pests (Chen et al. 2015b, Murphy et al. 2016). The use of bacterial or fungal microbes as RNAi delivery vehicles appear promising for vector control and the next challenges in this field will be to use this approach to interfere with pathogen development within a vector.

Deployment strategies - Regardless of the nature of the anti-pathogenic phenotype, be it innate or engineered, a strategy to disseminate the symbiont effectively through the vector population to have a meaningful effect on disease incidence is required. Wolbachia-based approaches have a clear advantage in this regard as the bacteria can manipulate host reproduction by $\mathrm{CI}$ to spread, often rapidly, through vector populations. For example, Wolbachia was established into Ae. aegypti populations in Cairns, Australia, by release of infected adults (Hoffmann et al. 2011). Subsequent analysis of the infection frequency in mosquito populations two years after the release found the bacteria was near fixation at the release sites (Hoffmann et al. 2014). Other strategies have been proposed for bacteria that do not manipulate host reproduction, and these may be self-perpetuating or require continual releases depending on the biology of the symbiont and host. As mentioned above, one elegant 
approach used in paratransgenic strategies of Triatomine bugs exploits the unique coprophagic probing tendencies of R. prolixus (Durvasula et al. 1997). For readily culturable microbes, it has been suggested that dissemination of the microbe into mosquito populations could be achieved by spiking larval pools or by baiting sugar feeders (Schlein \& Müller 2015). For the former, the microbe would either need to be transstadially transmitted or the adult would need to imbibe the microbe soon after emergence from the pupal case. It appears that gut bacteria are cleared during metamorphosis between mosquito life stages (Moll et al. 2001), but transstadial transmission may occur when other tissues like the malpighian tubules act as a reservoir for reinfection (Chavshin et al. 2015). In semi-field cage experiments, both sugar feeding stations and release of infected males was shown to be an effective method to perpetuate Asaia through Anopheles generations (Mancini et al. 2016). Asaia can be horizontally acquired and vertically transmitted, both maternally and paternally, which could perpetuate the infection (Favia et al. 2007, Damiani et al. 2008). A better understanding of the vertical and horizontal transmission of microbes and factors that influence microbiome homeostasis and composition is required before we can develop effective strategies for microbial release.

Future directions for microbial control of arthropodborne disease - Although there is a rich history of insect symbiosis research, many questions are yet to be resolved, particularly with regard to vector microbiomes. For successful utilisation of microbes for applied control approaches several areas need to be addressed. Translating promising strategies that demonstrate that microbes can modulate vector competence in the lab to natural populations is a priority. For this to be achieved studies assessing the diversity of vector-associated microbes across diverse ecological niches is required. A related future direction is to examine both the host-microbe and host-microbe-pathogen tripartite interactions under differing environmental conditions such as temperature, as this variable has been shown to influence vector immunity and pathogen dynamics (Murdock et al. 2012). While a particular control strategy may be successfully implemented under one set of environmental and ecological variables, this may not hold true where conditions differ.

Another important area of future research is in understanding the factors that influence how microbes are acquired, maintained, and transmitted by vectors. This knowledge is essential for developing effective methods to deploy symbionts into a population. Dissemination of a symbiont into a vector population may be hindered by microbial competition within the host. For example, Wolbachia and other bacterial microbes such as Serratia and Asaia are antagonistic to one other (Hughes et al. 2014a, Rossi et al. 2015, Zink et al. 2015). Additionally, re-introduction of bacterial microbes into mosquitoes via a sugar meal was more successful when the native microbiota were suppressed by antibiotics, suggesting bacterial interactions in the gut dictate microbial colonisation (Ramirez et al. 2014). Cross kingdom interactions between bacteria and fungi, both positive and negative, were seen Aedes triseriatus and Aedes japonicus (Muturi et al. 2016a).
Microbial interactions have also be documented in tsetse flies and ticks (Boucias et al. 2013, Wang et al. 2013a, Fryxell \& DeBruyn 2016). As such, the issue of compatibility between microbial strategies could arise. For example, a Wolbachia based approach may interfere with an ISV strategy, as ISVs have recently been shown to be suppressed by Wolbachia antiviral activity (Schnettler et al. 2016). Furthermore, paratransgenic approaches using Asaia or Serratia may not be compatible with Wolbachia applied approaches. While such an occurrence could be overcome by assessing the most suitable approach for a particular invention, strategies that perpetuate and drive through populations may expand geographically and therefore preclude the use of another technology elsewhere. Furthermore, the compatibility between microbial-based approaches and other contemporary and conventional vector control strategies should be investigated.

Another challenge with using microbes that possess native anti-pathogenic effects is determining the mechanism(s) by which they interfere with pathogens. Studies are providing insights into the mechanism(s) of pathogen interference of Wolbachia (Pan et al. 2011, Caragata et al. 2013, Zhang et al. 2014), gut microbes (Azambuja et al. 2004, Cirimotich et al. 2011, Ramirez et al. 2014), and fungi (Valzano et al. 2016, Angleró-Rodríguez et al. 2016), however a more comprehensive mechanistic understanding would facilitate attempts to forecast the long-term evolutionary response of the pathogen to the intervention and assist in determining the most effective deployment regime for a particular approach. While attempts have been made to predict these long-term interactions (Bull \& Turelli 2013), there are still unknown factors in these systems which makes these evaluations difficult. In contrast to this, the mechanism by which paratransgenic approaches inhibit pathogens is known as the effector molecule or RNAi cassette is engineered into the microbe. However, this means that all paratransgenic approaches have the unavoidable consequence that the microbe is genetically altered in some fashion.

For the ultimate utility of paratransgenic approaches, society needs to be receptive to this technology. Demonstrating the widespread benefits of these approaches by completing thorough and transparent research will enable societies and governments to make an informed decision of the risks and benefits of these novel control strategies. Further to this, the adoption of novel approaches to limit horizontal transfer of the transgene or the use of microencapsulation to contain microbes from environmental exposure will further enhance the safety of this technology (Arora et al. 2015, Mandell et al. 2015, Rovner et al. 2015). The success of the Wolbachia strategy employed by the Eliminate Dengue Campaign can provide a blueprint for other microbial-based strategies to address ethical, social and logistical hurdles. In particular, this program has received wide-spread community acceptance that can be attributed to their comprehensive risk assessments and outstanding outreach and engagement efforts (McNaughton 2012, McNaughton \& Duong 2014, Murray et al. 2016).

Summary - While conventional vector control strategies have reduced the burden of some VBD, novel strategies are required. Microbial-based strategies are gaining traction as an alternative means to control VBD, as 
microbes have several desirable properties for applied control strategies, particularly the ability to disseminate through vector populations. Coupling this with the propensity of symbiotic microbes to interfere with pathogen development in the host or by engineering microbes to modulate vector competence vectors, microbial strategies offer great promise for control of important VBDs.

\section{AUTHORS' CONTRIBUTION}

All authors equally contributed to writing this paper.

\section{REFERENCES}

Afanasiev BN, Ward TW, Beaty BJ, Carlson JO. Transduction of Aedes aegypti mosquitoes with vectors derived from Aedes densovirus. Virology. 1999; 257: 62-72.

Akhoundi M, Bakhtiari R, Guillard T, Baghaei A, Tolouei R, Sereno $\mathrm{D}$, et al. Diversity of the bacterial and fungal microflora from the midgut and cuticle of phlebotomine sand flies collected in NorthWestern Iran. PLoS ONE. 2012; 7: e50259.

Aliota MT, Peinado SA, Velez ID, Osorio JE. The $w$ Mel strain of $W o l-$ bachia reduces transmission of Zika virus by Aedes aegypti. Sci Rep. 2061a; 6: 28792.

Aliota MT, Walker EC, Yepes AU, Velez ID, Christensen BM, Osorio JE. The $w \mathrm{Mel}$ strain of Wolbachia reduces transmission of Chikungunya virus in Aedes aegypti. PLoS Negl Trop Dis. 2016b; 10: e0004677.

Al-Salem WS, Pigott DM, Subramaniam K, Haines LR, Kelly-Hope $\mathrm{L}$, Molyneux DH, et al. Cutaneous leishmaniasis and conflict in Syria. Emerging Infect Dis. 2016; 22: 931-3.

Angleró-Rodríguez YI, Blumberg BJ, Dong Y, Sandiford SL, Pike A, Clayton AM, et al. A natural Anopheles-associated Penicillium chrysogenum enhances mosquito susceptibility to Plasmodium infection. Sci Rep. 2016; 6: 34084.

Apte-Deshpande A, Paingankar M, Gokhale MD, Deobagkar DN. Serratia odorifera a midgut inhabitant of Aedes aegypti mosquito enhances its susceptibility to Dengue-2 virus. PLoS ONE. 2012; 7: e40401.

Apte-Deshpande AD, Paingankar MS, Gokhale MD, Deobagkar DN. Serratia odorifera mediated enhancement in susceptibility of Aedes aegypti for Chikungunya virus. Indian J Med Res. 2014; 139: 762-8.

Arora AK, Forshaw A, Miller TA, Durvasula R. A delivery system for field application of paratransgenic control. BMC Biotechnol. 2015; 15 : 59.

Azambuja P, Feder D, Garcia ES. Isolation of Serratia marcescens in the midgut of Rhodnius prolixus: impact on the establishment of the parasite Trypanosoma cruzi in the vector. Exp Parasitol. 2004; 107: 89-96.

Bahia AC, Dong Y, Blumberg BJ, Mlambo G, Tripathi A, BenmarzoukHidalgo OJ, et al. Exploring Anopheles gut bacteria for Plasmodium blocking activity. Environ Microbiol. 2014; 16(9): 2980-94.

Baldini F, Segata N, Pompon J, Marcenac P, Shaw W, Dabiré RK, et al. Evidence of natural Wolbachia infections in field populations of Anopheles gambiae. Nat Commun. 2014; 5: 3985.

Ballard JWO, Melvin RG. Tetracycline treatment influences mitochondrial metabolism and mtDNA density two generations after treatment in Drosophila. Insect Mol Biol. 2007; 16: 799-802.

Bando H, Okado K, Guelbeogo WM, Badolo A, Aonuma H, Nelson $\mathrm{B}$, et al. Intra-specific diversity of Serratia marcescens in Anopheles mosquito midgut defines Plasmodium transmission capacity. Sci Rep. 2013; 3: 1641-9.

Barrett ADT. Yellow fever in Angola and beyond - the problem of vaccine supply and demand. N Engl J Med. 2016; 375: 301-303.
Baton LA, Pacidônio EC, Gonçalves DDS, Moreira LA. wFlu: characterization and evaluation of a native Wolbachia from the mosquito Aedes fluviatilis as a potential vector control agent. PLoS ONE. 2013; 8: e59619.

Beard CB, Cordon-Rosales C, Durvasula RV. Bacterial symbionts of the triatominae and their potential use in control of Chagas disease transmission. Annu Rev Entomol. 2002; 47: 123-141.

Beier MS, Pumpuni CB, Beier JC, Davis JR. Effects of para-aminobenzoic acid, insulin, and gentamicin on Plasmodium falciparum development in anopheline mosquitoes (Diptera: Culicidae). J Med Entomol. 1994; 31: 561-5.

Bern C. Chagas' disease. N Eng1 J Med. 2015; 373: 456-66.

Bhatt S, Gething PW, Brady OJ, Messina JP, Farlow AW, Moyes CL, et al. The global distribution and burden of dengue. Nature. 2013; 496: 504-7.

Bian G, Joshi D, Dong Y, Lu P, Zhou G, Pan X, et al. Wolbachia invades Anopheles stephensi populations and induces refractoriness to Plasmodium infection. Science. 2013; 340: 748-51.

Bisi DC, Lampe DJ. Secretion of anti-Plasmodium effector proteins from a natural Pantoea agglomerans isolate by using PelB and HlyA secretion signals. Appl Environ Microbiol. 2011; 77: 4669-75.

Blagrove MSC, Arias-Goeta C, Failloux A-B, Sinkins SP. Wolbachia strain $w \mathrm{Mel}$ induces cytoplasmic incompatibility and blocks dengue transmission in Aedes albopictus. Proc Natl Acad Sci USA. 2011; 109: 255-60.

Blitvich B, Firth A. Insect-specific Flaviviruses: a systematic review of their discovery, host range, mode of transmission, superinfection exclusion potential and genomic organization. Viruses. 2015; 7: 1927-59.

Boissière A, Tchioffo MT, Bachar D, Abate L, Marie A, Nsango SE, et al. Midgut microbiota of the malaria mosquito vector Anopheles gambiae and interactions with Plasmodium falciparum infection. PLoS Pathog. 2012; 8: e1002742.

Bolling B, Weaver S, Tesh R, Vasilakis N. Insect-specific virus discovery: significance for the arbovirus community. Viruses. 2015; 7: 4911-28

Bolling BG, Olea-Popelka FJ, Eisen L, Moore CG, Blair CD. Transmission dynamics of an insect-specific flavivirus in a naturally infected Culex pipiens laboratory colony and effects of co-infection on vector competence for West Nile virus. Virology. 2012; 427: 90-7.

Bongio NJ, Lampe DJ. Inhibition of Plasmodium berghei development in mosquitoes by effector proteins secreted from Asaia sp. bacteria using a novel native secretion signal. PLoS ONE. 2015; 10: e0143541.

Boucias DG, Kariithi HM, Bourtzis K, Schneider DI, Kelley K, Miller WJ, et al. Transgenerational transmission of the Glossina pallidipes hytrosavirus depends on the presence of a functional symbiome. PLoS ONE. 2013; 8: e61150.

Bourtzis K, Dobson SL, Xi Z, Rasgon JL, Calvitti M, Moreira LA, et al. Harnessing mosquito-Wolbachia symbiosis for vector and disease control. Acta Trop. 2014; 132(Supp1.): S150-63.

Briones AM, Shililu J, Githure J, Novak R, Raskin L. Thorsellia anophelis is the dominant bacterium in a Kenyan population of adult Anopheles gambiae mosquitoes. ISME J. 2008; 2: 74-82.

Broderick NA. Friend, foe or food? Recognition and the role of antimicrobial peptides in gut immunity and Drosophila-microbe interactions. Philos Trans R Soc Lond B Biol Sci. 2016; 371: 20150295.

Buarque DS, Gomes CM, Araújo RN, Pereira MH, Ferreira RC, Guarneri AA, et al. A new antimicrobial protein from the anterior midgut of Triatoma infestans mediates Trypanosoma cruzi establishment by controlling the microbiota. Biochimie. 2016; 123: 138-43.

Buchon N, Broderick NA, Lemaitre B. Gut homeostasis in a microbial world: insights from Drosophila melanogaster. Nat Rev Microbiol. 2013; 11: 615-26. 
Buck M, Nilsson LKJ, Brunius C, Dabiré RK, Hopkins R, Terenius O. Bacterial associations reveal spatial population dynamics in Anopheles gambiae mosquitoes. Sci Rep. 2016; 6: 1-9.

Bull JJ, Turelli M. Wolbachia versus dengue: evolutionary forecasts. Evol Med Public Health. 2013; 197-207.

Caragata EP, Rancès E, Hedges LM, Gofton AW, Johnson KN, O'Neill SL, et al. Dietary cholesterol modulates pathogen blocking by Wolbachia. PLoS Pathog. 2013; 9: e1003459.

Carissimo G, Pondeville E, McFarlane M, Dietrich I, Mitri C, Bischoff E, et al. Antiviral immunity of Anopheles gambiaeis highly compartmentalized, with distinct roles for RNA interference and gut microbiota. Proc Natl Acad Sci USA. 2015; 112: E176-85.

Casadevall A, Fang FC, Pirofski L-A. Microbial virulence as an emergent property: consequences and opportunities. PLoS Pathog. 2011; 7: e1002136.

Castro DP, Moraes CS, González MS, Ratcliffe NA, Azambuja P, Garcia ES. Trypanosoma cruzi immune response modulation decreases microbiota in Rhodnius prolixus gut and is crucial for parasite survival and development. PLoS ONE. 2012; 7: e36591.

Castro DP, Seabra SH, Garcia ES, de Souza W, Azambuja P. Trypanosoma cruzi: ultrastructural studies of adhesion, lysis and biofilm formation by Serratia marcescens. Exp Parasitol. 2007; 117: 201-7.

Chandler JA, Liu RM, Bennett SN. RNA shotgun metagenomic sequencing of northern California (USA) mosquitoes uncovers viruses, bacteria, and fungi. Front Microbiol. 2015; 6: 185.

Chavshin AR, Oshaghi MA, Vatandoost H, Yakhchali B, Zarenejad F, Terenius O. Malpighian tubules are important determinants of Pseudomonas transstadial transmission and longtime persistence in Anopheles stephensi. Parasit Vectors. 2015; 8: 36.

Chen S, Bagdasarian M, Walker ED. Elizabethkingia anophelis: molecular manipulation and interactions with mosquito hosts. Appl Environ Microbiol. 2015a; 81: 2233-43.

Chen X, Li L, Hu Q, Zhang B, Wu W, Jin F, et al. Expression of dsRNA in recombinant Isaria fumosorosea strain targets the TLR7 gene in Bemisia tabaci. BMC Biotechnol. 2015b; 15: 1.

Chouaia B, Rossi P, Epis S, Mosca M, Ricci I, Damiani C, et al. Delayed larval development in Anopheles mosquitoes deprived of Asaia bacterial symbionts. BMC Microbiol. 2012; 12(Suppl. 1): S2.

Cirimotich CM, Dong Y, Clayton AM, Sandiford SL, Souza-Neto JA, Mulenga M, et al. Natural microbe-mediated refractoriness to Plasmodium infection in Anopheles gambiae. Science. 2011; 332: 855-8.

Clayton KA, Gall CA, Mason KL, Scoles GA, Brayton KA. The characterization and manipulation of the bacterial microbiome of the Rocky Mountain wood tick, Dermacentor andersoni. Parasit Vectors. 2015; 8: 632.

Coon KL, Brown MR, Strand MR. Mosquitoes host communities of bacteria that are essential for development but vary greatly between local habitats. Mol Ecol. 2016; 25(22): 5806-26.

Coon KL, Vogel KJ, Brown MR, Strand MR. Mosquitoes rely on their gut microbiota for development. Mol Ecol. 2014; 23(11): 2727-39.

Crockett RK, Burkhalter K, Mead D, Kelly R, Brown J, Varnado W, et al. Culex flavivirus and West Nile virus in Culex quinquefasciatus populations in the southeastern United States. J Med Entomol. 2012; 49: 165-74.

da Mota FF, Marinho LP, Moreira CJC, Lima MM, Mello CB, Garcia ES, et al. Cultivation-independent methods reveal differences among bacterial gut microbiota in triatomine vectors of Chagas disease. PLoS Negl Trop Dis. 2012; 6: e1631.

Damiani C, Ricci I, Crotti E, Rossi P, Rizzi A, Scuppa P, et al. Paternal transmission of symbiotic bacteria in malaria vectors. Curr Biol. 2008; 18(23): R1087-8.
Dantas-Torres F, Chomel BB, Otranto D. Ticks and tick-borne diseases: a one health perspective. Trends Parasitol. 2012; 28: 437-46.

David MR, dos Santos LMB, Vicente ACP, Maciel-de-Freitas R. Effects of environment, dietary regime and ageing on the dengue vector microbiota: evidence of a core microbiota throughout Aedes aegypti lifespan. Mem Inst Oswaldo Cruz. 2016; 111(9): 577-87.

de Vooght L, Caljon G, de Ridder K, Van den Abbeele J. Delivery of a functional anti-trypanosome Nanobody in different tsetse fly tissues via a bacterial symbiont, Sodalis glossinidius. Microb Cell Fact. 2014; 13: 156.

de Vooght L, Caljon G, Stijlemans B, de Baetselier P, Coosemans M, Van den Abbeele J. Expression and extracellular release of a functional anti-trypanosome Nanobody ${ }^{\circledR}$ in Sodalis glossinidius, a bacterial symbiont of the tsetse fly. Microb Cell Fact. 2012; 11: 1.

Dennison NJ, Jupatanakul N, Dimopoulos G. The mosquito microbiota influences vector competence for human pathogens. Curr Opin Insect Sci. 2014; 3: 6-13.

Dong Y, Manfredini F, Dimopoulos G. Implication of the mosquito midgut microbiota in the defense against malaria parasites. PLoS Pathog. 2009; 5: e1000423.

Dong Y, Morton JC, Ramirez JL, Souza-Neto JA, Dimopoulos G. The entomopathogenic fungus Beauveria bassiana activate toll and JAK-STAT pathway-controlled effector genes and anti-dengue activity in Aedes aegypti. Insect Biochem Mol Biol. 2012; 42: 126-32.

Duguma D, Hall MW, Rugman-Jones P, Stouthamer R, Terenius O, Neufeld JD, et al. Developmental succession of the microbiome of Culex mosquitoes. BMC Microbiol. 2015; 15: 140.

Duron O, Bouchon D, Boutin S, Bellamy L, Zhou L, Engelstädter J, et al. The diversity of reproductive parasites among arthropods: Wolbachia do not walk alone. BMC Biol. 2008; 6: 27.

Durvasula RV, Gumbs A, Panackal A, Kruglov O, Aksoy S, Merrifield RB, et al. Prevention of insect-borne disease: an approach using transgenic symbiotic bacteria. Proc Natl Acad Sci USA. 1997; 94: 3274-8.

Durvasula RV, Kroger A, Goodwin M, Panackal A, Kruglov O, Taneja J, et al. Strategy for introduction of foreign genes into field populations of Chagas disease vectors. Ann Entomol Soc Am. 1999; 92: 937-43.

Dutra HLC, Rocha MN, Dias FBS, Mansur SB, Caragata EP, Moreira LA. Wolbachia blocks currently circulating Zika virus isolates in Brazilian Aedes aegypti mosquitoes. Cell Host Microbe. 2016; 19(6): 771-4.

Eichler S, Schaub GA. Development of symbionts in Triatomine bugs and the effects of infections with Trypanosomatids. Exp Parasitol. 2002; 100: 17-27.

Engel P, Moran NA. The gut microbiota of insects - diversity in structure and function. FEMS Microbiol Rev. 2013; 37: 699-735.

Erkosar B, Storelli G, Defaye A, Leulier F. Host-intestinal microbiota mutualism: "learning on the fly". Cell Host Microbe. 2013; 13: 8-14.

Fang W, Vega-Rodriguez J, Ghosh AK, Jacobs-Lorena M, Kang A, St Leger RJ. Development of transgenic fungi that kill human malaria parasites in mosquitoes. Science. 2011; 331(6020): 1074-7.

Favia G, Ricci I, Damiani C, Raddadi N, Crotti E, Marzorati M, et al. Bacteria of the genus Asaia stably associate with Anopheles stephensi, an Asian malarial mosquito vector. Proc Natl Acad Sci USA. 2007; 104: 9047-51.

Figueira-Mansur J, Ferreira-Pereira A, Mansur JF, Franco TA, Alvarenga ESL, Sorgine MHF, et al. Silencing of P-glycoprotein increases mortality in temephos-treated Aedes aegypti larvae. Insect Mol Biol. 2013; 22: 648-58.

Frank T, Gody JC, Nguyen LBL, Berthet N, Le Fleche-Mateos A, Bata P, et al. First case of Elizabethkingia anophelis meningitis in the Central African Republic. Lancet. 2013; 381: 1876. 
Fryxell RTT, DeBruyn JM. The microbiome of Ehrlichia-infected and uninfected lone star ticks (Amblyomma americanum). PLoS ONE. 2016; 11(1): e 0146651.

Gall CA, Reif KE, Scoles GA, Mason KL, Mousel M, Noh SM, et al. The bacterial microbiome of Dermacentor andersoni ticks influences pathogen susceptibility. ISME J. 2016; 10(8): 1846-55.

Garay JAR, Hughes GL, Koundal V, Rasgon JL, Mwangi MM. Genome sequence of Elizabethkingia anophelis strain EaAs1, isolated from the Asian malaria mosquito Anopheles stephensi. Genome Announc. 2016; 4(2): e00084-16.

Garver LS, Dong Y, Dimopoulos G. Caspar controls resistance to Plasmodium falciparum in diverse anopheline species. PLoS Pathog. 2009; 5: e1000335.

Genes C, Baquero E, Echeverri F, Maya JD, Triana O. Mitochondrial dysfunction in Trypanosoma cruzi: the role of Serratia marcescens prodigiosin in the alternative treatment of Chagas disease. Parasit Vectors. 2011; 4: 66.

Gimonneau G, Tchioffo MT, Abate L, Boissière A, Awono-Ambene PH, Nsango SE, et al. Composition of Anopheles coluzzii and Anopheles gambiae microbiota from larval to adult stages. Infect Genet Evol. 2014; 28: 715-724.

Glaser RL, Meola MA. The native Wolbachia endosymbionts of Drosophila melanogaster and Culex quinquefasciatus increase host resistance to West Nile Virus infection. PLoS ONE. 2010; 5(8): e11977.

Gu J-B, Dong Y-Q, Peng H-J, Chen X-G. A recombinant AeDNA containing the insect-specific toxin, BmK IT1, displayed an increasing pathogenicity on Aedes albopictus. Am J Trop Med Hyg. 2010; 83: 614-23

Gusmão DS, Santos AV, Marini DC, Bacci M, Berbert-Molina MA, Lemos FJA. Culture-dependent and culture-independent characterization of microorganisms associated with Aedes aegypti (Diptera: Culicidae) (L.) and dynamics of bacterial colonization in the midgut. Acta Trop. 2010; 115: 275-281.

Hall-Mendelin S, McLean BJ, Bielefeldt-Ohmann H, Hobson-Peters J, Hall RA, van den Hurk AF. The insect-specific Palm Creek virus modulates West Nile virus infection in and transmission by Australian mosquitoes. Parasit Vectors. 2016; 9(1): 414.

Hedges LM, Brownlie JC, O'Neill SL, Johnson KN. Wolbachia and virus protection in insects. Science. 2008; 322(5902): p. 702.

Hegde S, Rasgon JL, Hughes GL. The microbiome modulates arbovirus transmission in mosquitoes. Curr Opin Virol. 2015; 15: 97-102.

Hilgenboecker K, Hammerstein P, Schlattmann P, Telschow A, Werren JH. How many species are infected with Wolbachia? - A statistical analysis of current data. FEMS Microbiol Lett. 2008; 281: 215-20.

Hillesland H, Read A, Subhadra B, Hurwitz I, McKelvey R, Ghosh K, et al. Identification of aerobic gut bacteria from the kala azar vector, Phlebotomus argentipes: a platform for potential paratransgenic manipulation of sand flies. Am J Trop Med Hyg. 2008; 79: 881-6.

Hoffmann AA, Iturbe-Ormaetxe I, Callahan AG, Phillips BL, Billington $\mathrm{K}$, Axford JK, et al. Stability of the wMel Wolbachia infection following invasion into Aedes aegypti populations. PLoS Negl Trop Dis. 2014; 8: e3115.

Hoffmann AA, Montgomery BL, Popovici J, Iturbe-Ormaetxe I, Johnson PH, Muzzi F, et al. Successful establishment of Wolbachia in Aedes populations to suppress dengue transmission. Nature. 2011; 476: 454-7.

Hughes GL, Allsopp PG, Webb RI, Yamada R, Iturbe-Ormaetxe I, Brumbley SM, et al. Identification of yeast associated with the planthopper, Perkinsiella saccharicida: potential applications for Fiji leaf gall control. Curr Microbiol. 2011a; 63: 392-401.
Hughes GL, Dodson BL, Johnson RM, Murdock CC, Tsujimoto H, Suzuki Y, et al. Native microbiome impedes vertical transmission of Wolbachia in Anopheles mosquitoes. Proc Natl Acad Sci USA. 2014a; 111: 12498-12503.

Hughes GL, Koga R, Xue P, Fukatsu T, Rasgon JL. Wolbachia infections are virulent and inhibit the human malaria parasite Plasmodium falciparum in Anopheles gambiae. PLoS Pathog. 2011b; 7: e1002043.

Hughes GL, Rasgon JL. Transinfection: a method to investigate Wolbachia-host interactions and control arthropod-borne disease. Insect Mol Biol. 2014; 23: 141-51.

Hughes GL, Rivero A, Rasgon JL. Wolbachia can enhance Plasmodium infection in mosquitoes: implications for malaria control? PLoS Pathog. 2014b; 10: e1004182.

Hughes GL, Vega-Rodriguez J, Xue P, Rasgon JL. Wolbachia strain wAlbB enhances infection by the rodent malaria parasite Plasmodium berghei in Anopheles gambiae mosquitoes. Appl Environ Microbiol. 2012; 78: 1491-5.

Hurk AFVD, Hall-Mendelin S, Pyke AT, Frentiu FD, Mcelroy K, Day A, et al. Impact of Wolbachia on infection with Chikungunya and Yellow Fever viruses in the mosquito vector Aedes aegypti. PLoS Negl Trop Dis. 2012; 6: e1892.

Ignatova EA, Nagornaia SS, Povazhnaia TN, Ianishevskaia GS. The yeast flora of blood-sucking mosquitoes. Mikrobiol Z. 1996; 58(2): $12-15$.

Isoe J, Collins J, Badgandi H, Day WA, Miesfeld RL. Defects in coatomer protein I (COPI) transport cause blood feeding-induced mortality in Yellow Fever mosquitoes. Proc Natl Acad Sci USA. 2011; 108: E211-7.

Jasinskas A, Zhong J, Barbour AG. Highly prevalent Coxiella sp. bacterium in the tick vector Amblyomma americanum. Appl Environ Microbiol. 2007; 73: 334-6.

Jeffries CL, Walker T. The potential use of Wolbachia-based mosquito biocontrol strategies for Japanese encephalitis. PLoS Negl Trop Dis. 2015; 9: e0003576.

Jeffries CL, Walker T. Wolbachia biocontrol strategies for arboviral diseases and the potential influence of resident Wolbachia strains in mosquitoes. Curr Trop Med Rep. 2016; 3: 20-5.

Joshi D, McFadden MJ, Bevins D, Zhang F, Xi Z. Wolbachia strain w AlbB confers both fitness costs and benefit on Anopheles stephensi. Parasit Vectors. 2014; 7: 336.

Joubert DA, Walker T, Carrington LB, de Bruyne JT, Kien DHT, Hoang NT, et al. Establishment of a Wolbachia superinfection in Aedes aegypti mosquitoes as a potential approach for future resistance management. PLoS Pathog. 2016; 12: e1005434.

Joyce JD, Nogueira JR, Bales AA, Pittman KE, Anderson JR. Interactions between La Crosse virus and bacteria isolated from the digestive tract of Aedes albopictus (Diptera: Culicidae). J Med Entomol. 2011; 48: 389-94.

Kambris Z, Blagborough AM, Pinto SB, Blagrove MSC, Godfray HCJ, Sinden RE, et al. Wolbachia stimulates immune gene expression and inhibits plasmodium development in Anopheles gambiae. PLoS Pathog. 2010; 6(10): e1001143.

Kambris Z, Cook PE, Phuc HK, Sinkins SP. Immune activation by life-shortening Wolbachia and reduced filarial competence in mosquitoes. Science. 2009; 326: 134-6.

Keene KM, Foy BD, Sánchez-Vargas I, Beaty BJ, Blair CD, Olson KE. RNA interference acts as a natural antiviral response to O'nyongnyong virus (Alphavirus; Togaviridae) infection of Anopheles gambiae. Proc Natl Acad Sci USA. 2004; 101: 17240-5. 
Kenney JL, Solberg OD, Langevin SA, Brault AC. Characterization of a novel insect-specific flavivirus from Brazil: potential for inhibition of infection of arthropod cells with medically important flaviviruses. J Gen Virol. 2014; 95: 2796-2808.

Kukutla P, Lindberg BG, Pei D, Rayl M, Yu W, Steritz M, et al. Insights from the genome annotation of Elizabethkingia anophelis from the malaria vector Anopheles gambiae. PLoS ONE. 2014; 9: e97715.

Kumar S, Molina-Cruz A, Gupta L, Rodrigues J, Barillas-Mury C. A peroxidase/dual oxidase system modulates midgut epithelial immunity in Anopheles gambiae. Science. 2010; 327: 1644-8.

Kuwata R, Isawa H, Hoshino K, Sasaki T, Kobayashi M, Maeda K, et al. Analysis of Mosquito-borne flavivirus superinfection in Culex tritaeniorhynchus (Diptera: Culicidae) cells persistently infected with $\mathrm{Cu}$ lex flavivirus (Flaviviridae). J Med Entomol. 2015; 52: 222-9.

Ledermann JP, Suchman EL, Black WC, Carlson JO. Infection and pathogenicity of the mosquito densoviruses AeDNV, HeDNV, and APeDNV in Aedes aegypti mosquitoes (Diptera: Culicidae). J Econ Entomol. 2004; 97: 1828-35.

Lemaitre B, Nicolas E, Michaut L, Reichhart J-M, Hoffmann JA. The dorsoventral regulatory gene cassette spätzle/Toll/cactus controls the potent antifungal response in drosophila adults. Cell. 1996; 86: 973-83.

Leonard JN, Schaffer DV. Computational design of antiviral RNA interference strategies that resist human immunodeficiency virus escape. J Virol. 2005; 79: 1645-54.

Lewis Z, Lizé A. Insect behaviour and the microbiome. Curr Opin Insect Sci. 2015; 9: 86-90.

Liu P, Li X, Gu J, Dong Y, Liu Y, Santhosh P, et al. Development of non-defective recombinant densovirus vectors for microRNA delivery in the invasive vector mosquito, Aedes albopictus. Sci Rep. 2016; 6: 20979.

Maltz MA, Weiss BL, O’Neill M, Wu Y, Aksoy S. OmpA-mediated biofilm formation is essential for the commensal bacterium $\mathrm{So}$ dalis glossinidius to colonize the tsetse fly gut. Appl Environ Microbiol. 2012; 78: 7760-8.

Mancini MV, Spaccapelo R, Damiani C, Accoti A, Tallarita M, Petraglia E, et al. Paratransgenesis to control malaria vectors: a semifield pilot study. Parasit Vectors. 2016; 9: 140.

Mandell DJ, Lajoie MJ, Mee MT, Takeuchi R, Kuznetsov G, Norville JE, et al. Biocontainment of genetically modified organisms by synthetic protein design. Nature. 2015; 518(7537): 55-60.

Marti GA, Lastra CCL, Pelizza SA, García JJ. Isolation of Paecilomyces lilacinus (Thom) Samson (Ascomycota: Hypocreales) from the Chagas disease vector, Triatoma infestans Klug (Hemiptera: Reduviidae) in an endemic area in Argentina. Mycopathologia. 2006; 162: 369-72.

Martin E, Bongiorno G, Giovati L, Montagna M, Crotti E, Damiani $\mathrm{C}$, et al. Isolation of a Wickerhamomyces anomalus yeast strain from the sandfly Phlebotomus perniciosus, displaying the killer phenotype. Med Vet Entomol. 2015; 1: 101-6.

McNaughton D, Duong TTH. Designing a community engagement framework for a new dengue control method: a case study from central Vietnam. PLoS Negl Trop Dis. 2014; 8: e2794.

McNaughton D. The importance of long-term social research in enabling participation and developing engagement strategies for new dengue control technologies. PLoS Negl Trop Dis. 2012; 6: e1785.

Medlock J, Atkins KE, Thomas DN, Aksoy S, Galvani AP. Evaluating paratransgenesis as a potential control strategy for African Trypanosomiasis. PLoS Negl Trop Dis. 2013; 7: e2374.

Menchaca AC, Visi DK, Strey OF, Teel PD, Kalinowski K, Allen MS, et al. Preliminary assessment of microbiome changes following blood-feeding and survivorship in the Amblyomma americanum nymph-to-adult transition using semiconductor sequencing. PLoS ONE. 2013; 8: e67129.

Minard G, Tran FH, Raharimalala FN, Hellard E, Ravelonandro P, Mavingui $\mathrm{P}$, et al. Prevalence, genomic and metabolic profiles of Acinetobacter and Asaia associated with field-caught Aedes albopictus from Madagascar. FEMS Microbiol Ecol. 2013; 83: 63-73.

Moll RM, Romoser WS, Modrakowski MC, Moncayo AC, Lerdthusnee K. Meconial peritrophic membranes and the fate of midgut bacteria during mosquito (Diptera: Culicidae) metamorphosis. J Med Entomol. 2001; 38: 29-32.

Moreira LA, Iturbe-Ormaetxe I, Jeffery JA, Lu G, Pyke AT, Hedges LM, et al. A Wolbachia symbiont in Aedes aegypti limits infection with Dengue, Chikungunya, and Plasmodium. Cell. 2009; 139: 1268-78.

Mourya DT, Soman RS. Effect of gregarine parasite, Ascogregarina culicis \& tetracycline on the susceptibility of Culex bitaeniorhynchus to JE virus. Indian J Med Res. 1985; 81: 247-50.

Mousson L, Martin E, Zouache K, Madec Y, Mavingui P, Failloux AB. Wolbachia modulates Chikungunya replication in Aedes albopictus. Mol Ecol. 2010; 19: 1953-64.

Mousson L, Zouache K, Arias-Goeta C, Raquin V, Mavingui P, Failloux A-B. The native Wolbachia symbionts limit transmission of dengue virus in Aedes albopictus. PLoS Negl Trop Dis. 2012; 6: e1989.

Murdock CC, Blanford S, Hughes GL, Rasgon JL, Thomas MB. Temperature alters Plasmodium blocking by Wolbachia. Sci Rep. 2014; 4: 3932.

Murdock CC, Paaijmans KP, Cox-Foster D, Read AF, Thomas MB. Rethinking vector immunology: the role of environmental temperature in shaping resistance. Nat Rev Microbiol. 2012; 10: 869-76.

Murphy KA, Tabuloc CA, Cervantes KR, Chiu JC. Ingestion of genetically modified yeast symbiont reduces fitness of an insect pest via RNA interference. Sci Rep. 2016; 6: 22587.

Murray JV, Jansen CC, de Barro P. Risk associated with the release of Wolbachia-infected Aedes aegypti mosquitoes into the environment in an effort to control dengue. Front Public Health. 2016; 4: 43.

Muturi EJ, Bara JJ, Rooney AP, Hansen AK. Midgut fungal and bacterial microbiota of Aedes triseriatus and Aedes japonicus shift in response to la crosse virus infection. Mol Ecol. 2016a; 25(16): 4075-90.

Muturi EJ, Ramirez JL, Rooney AP, Dunlap C. Association between fertilizer-mediated changes in microbial communities and Aedes albopictus growth and survival. Acta Trop. 2016b; 164: 54-63.

Naqqash MN, Gökçe A, Bakhsh A, Salim M. Insecticide resistance and its molecular basis in urban insect pests. Parasitol Res. 2016; 115: $1363-73$.

Narasimhan S, Rajeevan N, Liu L, Zhao YO, Heisig J, Pan J, et al. Gut microbiota of the tick vector Ixodes scapularis modulate colonization of the lyme disease Spirochete. Cell Host Microbe. 2014; 15(1): 58-71.

Nasar F, Gorchakov RV, Tesh RB, Weaver SC. Eilat virus host range restriction is present at multiple levels of the virus life cycle. $\mathrm{J}$ Virol. 2015; 89: 1404-18.

Newman CM, Cerutti F, Anderson TK, Hamer GL, Walker ED, Kitron UD, et al. Culex flavivirus and west Nile virus mosquito coinfection and positive ecological association in Chicago, United States. Vector Borne Zoonotic Dis. 2011; 11(8): 1099-1105.

Ng TFF, Willner DL, Lim YW, Schmieder R, Chau B, Nilsson C, et al. Broad surveys of DNA viral diversity obtained through viral metagenomics of mosquitoes. PLoS ONE. 2011; 6: e20579.

Noden BH, Vaughan JA, Pumpuni CB, Beier JC. Mosquito ingestion of antibodies against mosquito midgut microbiota improves conversion of ookinetes to oocysts for Plasmodium falciparum, but not P. yoelii. Parasitol Int. 2011; 60: 440-6. 
O’Connor L, Plichart C, Sang AC, Brelsfoard CL, Bossin HC, Dobson SL. Open release of male mosquitoes infected with a wolbachia biopesticide: field performance and infection containment. PLoS Negl Trop Dis. 2012; 6: e1797.

Oliveira JHM, Gonçalves RLS, Lara FA, Dias FA, Gandara ACP, Menna-Barreto RFS, et al. Blood meal-derived heme decreases ROS levels in the midgut of Aedes aegypti and allows proliferation of intestinal microbiota. PLoS Pathog. 2011; 7: e1001320.

Osei-Poku J, Mbogo CM, Palmer WJ, Jiggins FM. Deep sequencing reveals extensive variation in the gut microbiota of wild mosquitoes from Kenya. Mol Ecol. 2012; 21: 5138-50.

Pan X, Zhou G, Wu J, Bian G, Lu P, Raikhel AS, et al. Wolbachia induces reactive oxygen species (ROS)-dependent activation of the Toll pathway to control dengue virus in the mosquito Aedes aegypti. Proc Natl Acad Sci USA. 2011; 109(1): E23-31.

Pang X, Xiao X, Liu Y, Zhang R, Liu J, Liu Q, et al. Mosquito C-type lectins maintain gut microbiome homeostasis. Nat Microbiol. 2016; 1: 16023.

Pei D, Jiang J, Yu W, Kukutla P, Uentillie A, Xu J. The waaL gene mutation compromised the inhabitation of Enterobacter sp. Ag1 in the mosquito gut environment. Parasit Vectors. 2015; 8: 437.

Ramirez JL, Short SM, Bahia AC, Saraiva RG, Dong Y, Kang S, et al. Chromobacterium Csp_P reduces malaria and dengue infection in vector mosquitoes and has entomopathogenic and in vitro antipathogen activities. PLoS Pathog. 2014; 10: e1004398.

Ramirez JL, Souza-Neto J, Cosme RT, Rovira J, Ortiz A, Pascale JM, et al. Reciprocal tripartite interactions between the Aedes aegypti midgut microbiota, innate immune system and dengue virus influences vector competence. PLoS Negl Trop Dis. 2012; 6: e1561.

Ranson H, Lissenden N. Insecticide resistance in African Anopheles mosquitoes: a worsening situation that needs urgent action to maintain malaria control. Trends Parasitol. 2016; 32: 187-96.

Ren X, Hoiczyk E, Rasgon JL. Viral paratransgenesis in the malaria vector Anopheles gambiae. PLoS Pathog. 2008; 4: e1000135.

Ren X, Hughes GL, Niu G, Suzuki Y, Rasgon JL. Anopheles gambiae densovirus (AgDNV) has negligible effects on adult survival and transcriptome of its mosquito host. PeerJ. 2014; 2: e584.

Ricci I, Damiani C, Scuppa P, Mosca M, Crotti E, Rossi P, et al. The yeast Wickerhamomyces anomalus (Pichia anomala) inhabits the midgut and reproductive system of the Asian malaria vector Anopheles stephensi. Environ Microbiol. 2011; 13(4): 911-21.

Ricci I, Mosca M, Valzano M, Damiani C, Scuppa P, Rossi P, et al. Different mosquito species host Wickerhamomyces anomalus (Pichia anomala): perspectives on vector-borne diseases symbiotic control. Antonie Van Leeuwenhoek. 2010; 99(1): 43-50.

Riehle MA, Moreira CK, Lampe D, Lauzon C, Jacobs-Lorena M. Using bacteria to express and display anti-Plasmodium molecules in the mosquito midgut. Int J Parasitol. 2007; 37: 595-603.

Rodrigues J, Brayner FA, Alves LC, Dixit R, Barillas-Mury C. Hemocyte differentiation mediates innate immune memory in Anopheles gambiae mosquitoes. Science. 2010; 329: 1353-5.

Rossi P, Ricci I, Cappelli A, Damiani C, Ulissi U, Mancini MV, et al. Mutual exclusion of Asaia and Wolbachia in the reproductive organs of mosquito vectors. Parasit Vectors. 2015; 8: 278.

Rovner AJ, Haimovich AD, Katz SR, Li Z, Grome MW, Gassaway $\mathrm{BM}$, et al. Recoded organisms engineered to depend on synthetic amino acids. Nature. 2015; 518(7537): 89-93.

Sakamoto JM, Ng TFF, Suzuki Y, Tsujimoto H, Deng X, Delwart E, et al. Bunyaviruses are common in male and female Ixodes scapularis ticks in central Pennsylvania. PeerJ. 2016; 4: e2324-9.
Sánchez-Vargas I, Scott JC, Poole-Smith BK, Franz AWE, BarbosaSolomieu V, Wilusz J, et al. Dengue virus type 2 infections of Aedes aegypti are modulated by the mosquito's RNA interference pathway. PLoS Pathog. 2009; 5: e1000299.

Schlein Y, Müller GC. Decrease of larval and subsequent adult Anopheles sergentii populations following feeding of adult mosquitoes from Bacillus sphaericus- containing attractive sugar baits. Parasit Vectors. 2015; 8: 244.

Schlein Y, Polacheck I, Yuval B. Mycoses, bacterial infections and antibacterial activity in sandflies (Psychodidae) and their possible role in the transmission of leishmaniasis. Parasitology. 1985; 90(Pt 1): 57-66.

Schnettler E, Sreenu VB, Mottram T, McFarlane M. Wolbachia restricts insect specific flavivirus infection in Aedes aegypti cells. J Gen Virol. 2016; 97(11): 3024-9.

Segata N, Baldini F, Pompon J, Garrett WS, Truong DT, Dabiré RK, et al. The reproductive tracts of two malaria vectors are populated by a core microbiome and by gender- and swarm-enriched microbial biomarkers. Sci Rep. 2016; 6: 24207.

Sharma P, Sharma S, Maurya RK, de Das T, Thomas T, Lata S, et al. Salivary glands harbor more diverse microbial communities than gut in Anopheles culicifacies. Parasit Vectors. 2014; 7: 235.

Shaw WR, Marcenac P, Childs LM, Buckee CO, Baldini F, Sawadogo SP, et al. Wolbachia infections in natural Anopheles populations affect egg laying and negatively correlate with Plasmodium development. Nat Commun. 2016; 7: 11772.

Shropshire JD, Bordenstein SR. Speciation by symbiosis: the microbiome and behavior. MBio. 2016; 7: e01785.

Snow RW, Guerra CA, Noor AM, Myint HY, Hay SI. The global distribution of clinical episodes of Plasmodium falciparum malaria. Nature. 2005; 434: 214-7.

Soares TS, Buarque DS, Queiroz BR, Gomes CM, Braz GRC, Araújo RN, et al. A Kazal-type inhibitor is modulated by Trypanosoma cruzi to control microbiota inside the anterior midgut of Rhodnius prolixus. Biochimie. 2015; 112: 41-8.

Souza-Neto JA, Sim S, Dimopoulos G. An evolutionary conserved function of the JAK-STAT pathway in anti-dengue defense. Proc Natl Acad Sci USA. 2009; 106: 17841-6.

Stathopoulos S, Neafsey DE, Lawniczak MKN, Muskavitch MAT, Christophides GK. Genetic dissection of Anopheles gambiae gut epithelial responses to Serratia marcescens. PLoS Pathog. 2014; 10: e1003897.

Steyn A, Roets F, Botha A. Yeasts associated with Culex pipiens and Culex theileri mosquito larvae and the effect of selected yeast strains on the ontogeny of Culex pipiens. Microb Ecol. 2015; 71(3): 747-60.

Straif SC, Mbogo CN, Toure AM, Walker ED, Kaufman M, Toure YT, et al. Midgut bacteria in Anopheles gambiae and An. funestus (Diptera: Culicidae) from Kenya and Mali. J Med Entomol. 1998; 35: 222-6.

Suzuki Y, Niu G, Hughes GL, Rasgon JL. A viral over-expression system for the major malaria mosquito Anopheles gambiae. Sci Rep. 2014; 4: 5127.

Taracena ML, Oliveira PL, Almendares O, Umaña C, Lowenberger $\mathrm{C}$, Dotson EM, et al. Genetically modifying the insect gut microbiota to control Chagas disease vectors through systemic RNAi. PLoS Negl Trop Dis. 2015; 9: e0003358-14.

Tchioffo MT, Boissière A, Abate L, Nsango SE, Bayibéki AN, AwonoAmbene PH, et al. Dynamics of bacterial community composition in the malaria mosquito's epithelia. Front Microbiol. 2016; 6: 3985.

Teixeira L, Ferreira A, Ashburner M. The bacterial symbiont Wolbachia induces resistance to RNA viral infections in Drosophila melanogaster. PLoS Biol. 2008; 6: e2. 
Teo J, Tan SY-Y, Liu Y, Tay M, Ding Y, Li Y, et al. Comparative genomic analysis of malaria mosquito vector-associated novel pathogen Elizabethkingia anophelis. Genome Biol Evol. 2015; 6: 1158-65.

Terenius O, de Oliveira CD, Pinheiro WD, Tadei WP, James AA, Marinotti O. 16S rRNA gene sequences from bacteria associated with adult Anopheles darlingi (Diptera: Culicidae) mosquitoes. J Med Entomol. 2008; 45: 172-5.

Thailayil J, Magnusson K, Godfray HCJ, Crisanti A, Catteruccia F. Spermless males elicit large-scale female responses to mating in the malaria mosquito Anopheles gambiae. Proc Natl Acad Sci USA. 2011; 108: 13677-81.

Timmons L, Court DL, Fire A. Ingestion of bacterially expressed dsRNAs can produce specific and potent genetic interference in Caenorhabditis elegans. Gene. 2001; 263: 103-12.

Tokarz R, Williams SH, Sameroff S, Leon MS, Jain K, Lipkin WI. Virome analysis of Amblyomma americanum, Dermacentor variabilis, and Ixodes scapularis ticks reveals novel highly divergent vertebrate and invertebrate viruses. J Virol. 2014; 88: 11480-92.

Valzano M, Cecarini V, Cappelli A, Capone A, Bozic J, Cuccioloni $\mathrm{M}$, et al. A yeast strain associated to Anopheles mosquitoes produces a toxin able to kill malaria parasites. Malar J. 2016; 15: 21.

van Tol S, Dimopoulos G. Influences of the mosquito microbiota on vector competence. Adv In Insect Phys. 2016; 51: 243-91.

Vasilakis N, Tesh RB. Insect-specific viruses and their potential impact on arbovirus transmission. Curr Opin Virol. 2015; 15: 69-74.

Vieira CS, Mattos DP, Waniek PJ, Santangelo JM, Figueiredo MB, Gumiel M, et al. Rhodnius prolixus interaction with Trypanosoma rangeli: modulation of the immune system and microbiota population. Parasit Vectors. 2015; 8: 135.

Walker T, Johnson PH, Moreira LA, Iturbe-Ormaetxe I, Frentiu FD, McMeniman CJ, et al. The wMel Wolbachia strain blocks dengue and invades caged Aedes aegypti populations. Nature. 2011; 476: 450-3.

Wang J, Brelsfoard C, Wu Y, Aksoy S. Intercommunity effects on microbiome and GpSGHV density regulation in tsetse flies. J Invertebr Pathol. 2013a; 112(Suppl.): S32-9.

Wang J, Weiss BL, Aksoy S. Tsetse fly microbiota: form and function. Front Cell Infect Microbiol. 2013b; 3: 69.

Wang J, Wu Y, Yang G, Aksoy S. Interactions between mutualist Wigglesworthia and tsetse peptidoglycan recognition protein (PGRPLB) influence trypanosome transmission. Proc Natl Acad Sci USA. 2009; 106: 12133-8.

Wang S, Ghosh AK, Bongio N, Stebbings KA, Lampe DJ, Jacobs-Lorena M. Fighting malaria with engineered symbiotic bacteria from vector mosquitoes. Proc Natl Acad Sci USA. 2012; 109: 12734-9.

Wang S, Jacobs-Lorena M. Genetic approaches to interfere with malaria transmission by vector mosquitoes. Trends Biotechnol. 2013; 31: 185-93.

Wang Y, Gilbreath TM, Kukutla P, Yan G, Xu J. Dynamic gut microbiome across life history of the Malaria mosquito Anopheles gambiae in Kenya. PLoS ONE. 2011; 6: e24767.
Wang Y-H, Hu Y, Xing L-S, Jiang H, Hu S-N, Raikhel AS, et al. A critical role for CLSP2 in the modulation of antifungal immune response in mosquitoes. PLoS Pathog. 2015; 11: e1004931.

Weaver SC, Costa F, Garcia-Blanco MA, Ko AI, Ribeiro GS, Saade $\mathrm{G}$, et al. Zika virus: history, emergence, biology, and prospects for control. Antiviral Research. 2016; 130: 69-80.

Weaver SC, Lecuit M. Chikungunya virus and the global spread of a mosquito-borne disease. N Engl J Med. 2015; 372: 1231-9.

Weiss BL, Wang J, Maltz MA, Wu Y, Aksoy S. Trypanosome infection establishment in the Tsetse fly gut is influenced by microbiomeregulated host immune barriers. PLoS Pathog. 2013; 9: e1003318.

Werren JH, Baldo L, Clark ME. Wolbachia: master manipulators of invertebrate biology. Nat Rev Microbiol. 2008; 6: 741-51.

Whitten MMA, Facey PD, Del Sol R, Fernández-Martínez LT, Evans MC, Mitchell JJ, et al. Symbiont-mediated RNA interference in insects. Proc Biol Sci. 2016; 283: 20160042.

Whyard S, Erdelyan CN, Partridge AL, Singh AD, Beebe NW, Capina R. Silencing the buzz: a new approach to population suppression of mosquitoes by feeding larvae double-stranded RNAs. Parasit Vectors. 2015; 8: 181-20

Xi Z, Ramirez JL, Dimopoulos G. The Aedes aegypti toll pathway controls dengue virus infection. PLoS Pathog. 2008; 4: e1000098.

Xia H, Hu C, Zhang D, Tang S, Zhang Z, Kou Z, et al. Metagenomic profile of the viral communities in Rhipicephalus spp. ticks from Yunnan, China. PLoS ONE. 2015; 10: e0121609.

Xie P-W, Xie Y, Zhang X-J, Huang H, He L-N, Wang X-J, et al. Inhibition of dengue virus 2 replication by artificial micrornas targeting the conserved regions. Nucleic Acid Ther. 2013; 23: 244-52.

Zélé F, Nicot A, Berthomieu A, Weill M, Duron O, Rivero A. Wolbachia increases susceptibility to Plasmodium infection in a natural system. Proc Biol Sci. 2014; 281: 20132837.

Zélé F, Nicot A, Duron O, Rivero A. Infection with Wolbachia protects mosquitoes against Plasmodium-induced mortality in a natural system. J Evol Biol. 2012; 25: 1243-52.

Zhang G, Hussain M, Asgari S. Regulation of arginine methyltransferase 3 by a Wolbachia-induced microRNA in Aedes aegypti and its effect on Wolbachia and dengue virus replication. Insect Biochem Mol Biol. 2014; 53: 81-8.

Zink S, van Slyke G, Palumbo M, Kramer L, Ciota A. Exposure to west nile virus increases bacterial diversity and immune gene expression in Culex pipiens. Viruses. 2015; 7: 5619-31.

Zouache K, Michelland RJ, Failloux A-B, Grundmann GL, Mavingui P. Chikungunya virus impacts the diversity of symbiotic bacteria in mosquito vector. Mol Ecol. 2012; 21(9): 2297-309.

Zouache K, Raharimalala FN, Raquin V, Tran-Van V, Raveloson LHR, Ravelonandro $\mathrm{P}$, et al. Bacterial diversity of field-caught mosquitoes, Aedes albopictus and Aedes aegypti, from different geographic regions of Madagascar. FEMS Microbiol Ecol. 2010; 75(3): 377-89. 